\title{
Improvement of the theory of shaft spillway calculations
}

\author{
Alim Gur'yev ${ }^{1 *}$, Nartmir Khanov ${ }^{1}$, Marina Chumicheva $^{1}$, Aleksandra Verkhoglyadova $^{1}$, \\ Buchra Hayek ${ }^{1}$, and Abderrezak Brakeni $^{2}$ \\ ${ }^{1}$ Russian State Agrarian University-Moscow Timiryazev Agricultural Academy, Moscow, Russia \\ ${ }^{2}$ University of Bejaia, Algeria
}

\begin{abstract}
Over the last hundred years, shaft spillways have become widely used in hydraulic engineering practice due to their undeniable advantages: high discharge capacity, maximal water consumption per one cubic meter of concrete, point structure compactness. The modern theory of hydraulic calculations was formed based on works on the study of the operation of a circular spillway with a sharp edge carried out by Wagner in 1954. Although numerous hydraulic studies have not proved many of the statements Wagner's calculation methodology was based on, the materials of his studies have been presented in special hydraulic literature for hydraulic calculations up to date. The accepted design conditions of the drainage surface of the spillway shaft, which is round-cylindrical in the cross-section and in the form of a convex parabolic line in the longitudinal section, do not correspond to the possibilities of work. As a result, the drainage surface is replaced by a system of truncated cones, the joints of which cause flow separation from the drainage surface and the formation of vacuum zones. It results in approximate hydraulic calculations. To eliminate these disadvantages of hydraulic calculations and bring design developments in line with technological possibilities of works, it is possible to replace a round-cylindrical cross-section of the inner surface of the shaft with a polygonal one. In this case, the drainage surface will consist of a system of longitudinal wedges with one-dimensional curvature, for which the formwork can be made of flat sheets. This paper presents materials on the calculation and design of a shaft spillway of a hydroelectric complex with a dodecagonal cross-section for Algeria, and four shafts with an octagonal cross-section and two shafts with a tetragonal cross-section for Syria. The receiving hopper head is round-cylindrical, and the drainage surface is elliptical, which allows adapting the drainage surface to any initial design parameters of shaft spillways.
\end{abstract}

\section{Introduction}

The first shat spillway was built in England in 1923 [1]. During the construction of Vsection waterworks, river diversion is made via diversion tunnels. According to various estimates, the cost of river diversion works can reach $30 \%$ of the cost of a hydroelectric

\footnotetext{
* Corresponding author: alim_guryev@mail.ru
} 
complex. As a rule, after constructing the structure, the diversion tunnels were taken out of service. To reduce construction costs, it was proposed to use diversion tunnels as spillways. For this purpose, shafts were built over the diversion tunnels through which flows were dumped. This is how the coastal shaft spillways appeared. The main disadvantage of these shaft spillways was the "poor hydraulics" of the receiving hopper due to flow failure. To eliminate that disadvantage, a large amount of earthwork had to be performed. The use of water approaches to the receiving hoppers led to the slope cutting and danger of landslides. To eliminate this drawback, the shafts of the spillways were started to be constructed into the water area of the reservoirs. This is how the shaft spillways appeared and currently a predominant construction. Figure 1 shows the shaft of a hydroelectric complex with a tower shaft spillway extended into the water area of the reservoir.

\section{Methods}

The profile of the inner surface of the first shaft spillways was outlined according to the Krieger coordinates. Figure 2 shows a longitudinal section of the San Valentino spillway shaft (Italy, 1953) [2]. The design and estimations of the shaft spillway were carried out based on the assumption that the receiving hopper is a rectilinear spillway with a Krieger profile, rolled into a ring. Therefore the shaft spillway discharge rate was taken a priori as the flow rate $\mathrm{m}=0.49$ of a vacuum-free spillway.

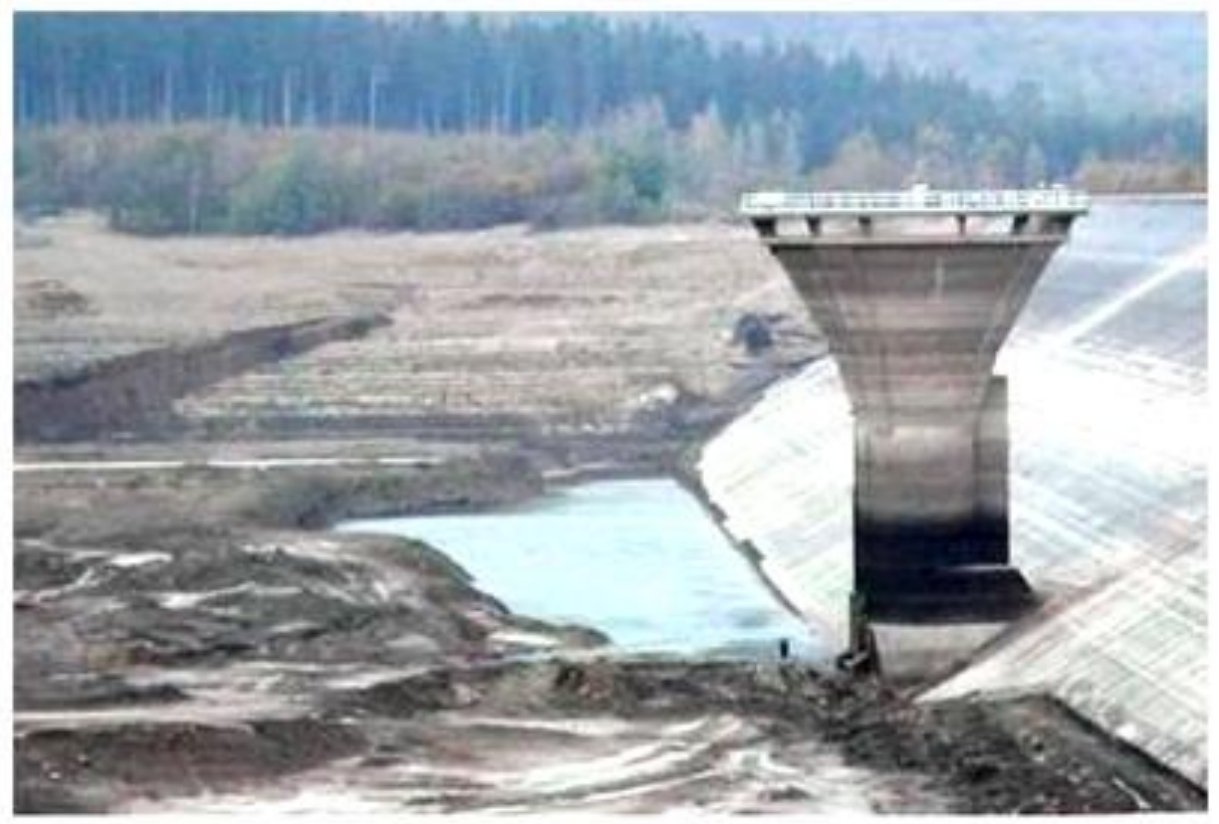

Fig. 1. Tower shaft spillway shaft 


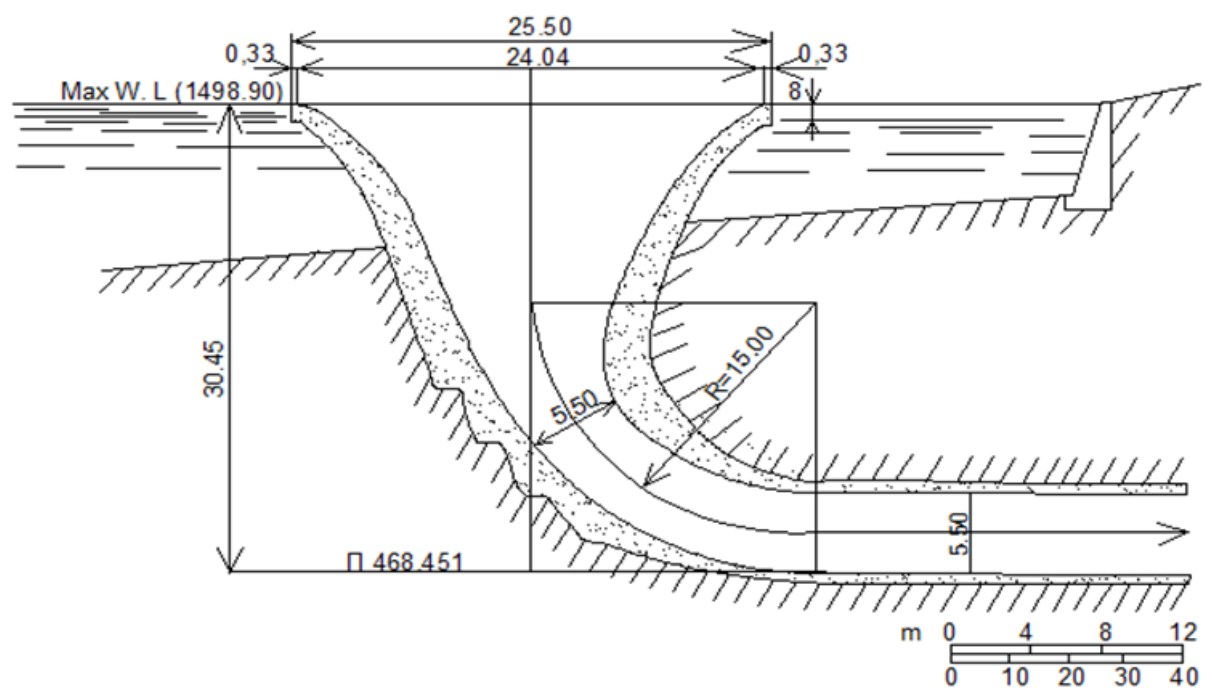

Fig. 2. Longitudinal section of the shaft spillway shaft of the San Valentino hydroelectric complex

The work of Wagner [3], in which the results of studies of the circular spillway with a sharp edge were presented, gave a great impetus to the further intensive use of shaft spillways. Based on the results of these studies, Wagner determined the parameters of the upper and lower surfaces of a free-falling jet. According to the data of these studies, Wagner outlined a vacuum-free spillway profile shaft in the non-dimensional coordinates $y / H=f(x / H=$ var, $p / H=$ const $)$ and the coefficient of discharge in the coordinates $m=f$ $(H / R=$ var, $p / R=$ const $)$. Although numerous further experiments did not confirm Wagner's premise about the vacuum-free character of the profiles of the spillway shaft surface proposed by him, up to date these materials are cited in the reference literature as recommended for the practice of hydraulic calculations of shaft spillways $[4,5,6]$.

Great deals of the studies of shaft spillways were carried out by P. P. Mois $[1,7,8]$.

First of all, P.P. Mois studied the pressure distribution in the under-flow space for different outlines of the spillway shaft surface and found vacuum despite the fact that these outlines were theoretically vacuum-free. To reduce the vacuum, P.P. Mois proposed an elliptical outline of the drainage surface, on which the least vacuum was formed in comparison with the vacuum on the drainage surfaces of other profiles. Figure 3 shows the graphs of changes in the maximum vacuum on the drainage surface of the hopper head $\left(h_{\text {vac }}\right)_{\max } / H=f(H / R)$, depending on its profile. 


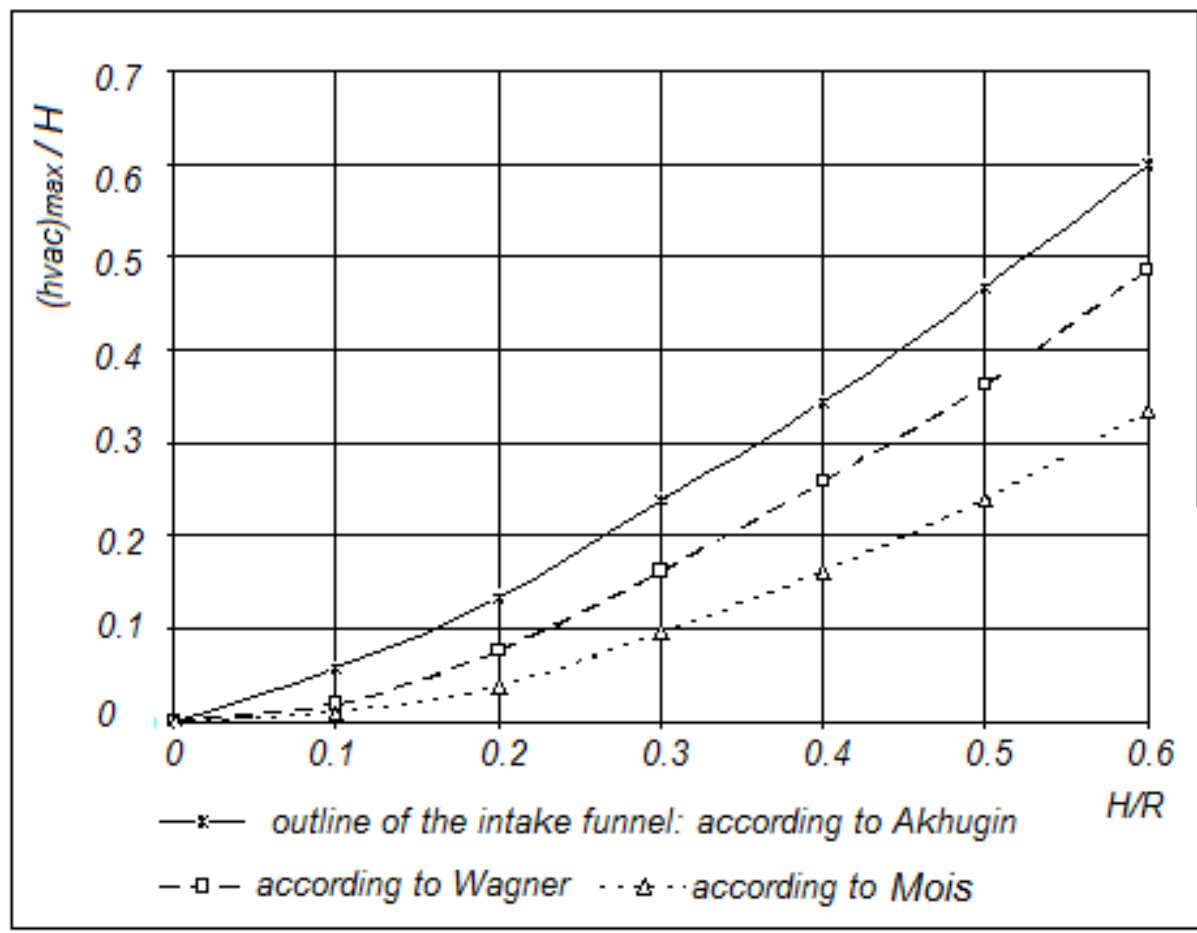

Fig. 3. Graphs of the maximum vacuum on the drainage surface of the hopper head $\left(h_{v a c}\right)_{\max } / H=f$ $(H / R)$ depending on its profile

The research results and recommendations of P.P. Mois are given only in the textbooks of L. N. Rasskazov [9, 10], [18-22].

The disadvantage of the existing hydraulic calculation methods of shaft spillways is the isolation from the technological capabilities of the work. The surface of the shaft spillway is a spatial surface with a double curvature: it has a circular cross-section with positive curvature and parabolic longitudinal surface sections with negative curvature. However, nowadays, there are no materials for making a formwork with a project drainage surface. Therefore, in the practice of hydraulic engineering, the project drainage surface is replaced by a system of truncated cones stacked on top of each other. The view of this surface is given by the drainage surface of the shaft spillway of the Monticello hydroelectric complex, USA, the photo of which is shown in Figure 4 [11]. 


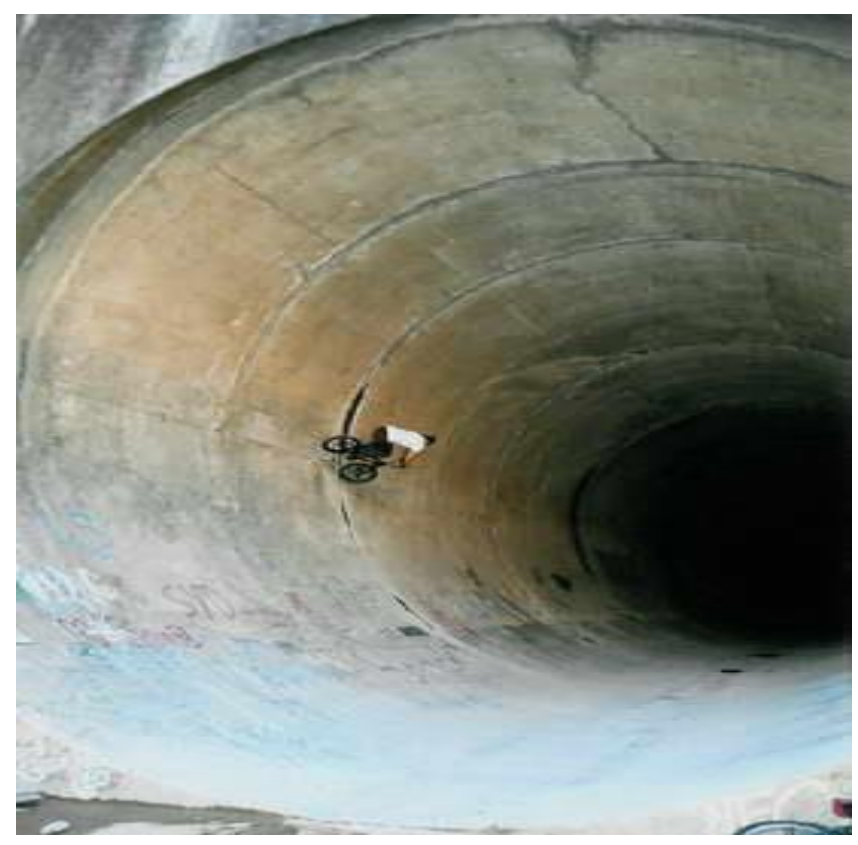

Fig. 4. Drainage surface of the shaft spillway of the Monticello hydroelectric complex

This figure clearly shows the joints of the sections which cause flow separation from the drainage surface with the formation of vacuum areas and cavitation erosion.

Figure 5 shows the inner surface of the coupled bends of the shaft spillways of the Regadera hydroelectric complex in Columbia and the Gibson hydroelectric complex in the USA [12].

According to Bradley, the impossibility to form the concrete surface of the waterconveyance system with the project outline is the main cause of the cavitation corrosion of concrete in the spillway bend. There was cavitation corrosion of concrete shown in Figure 5 when the discharge was only $48 \%$ of the estimated capacity.

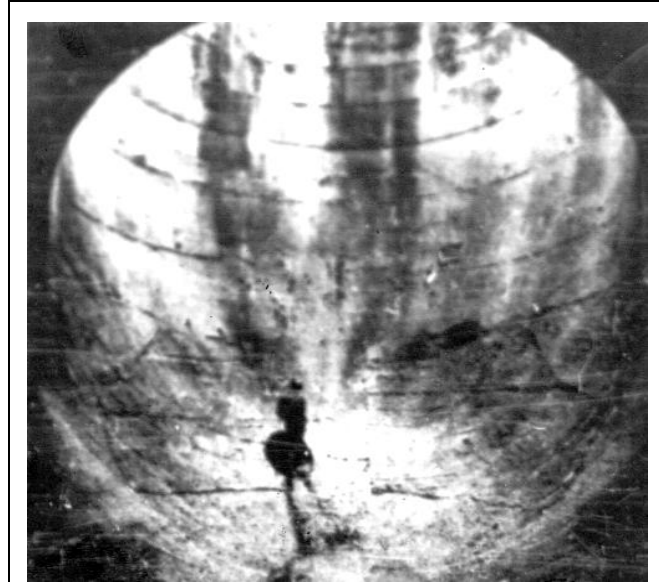

Regadera hydroelectric complex in Colombia

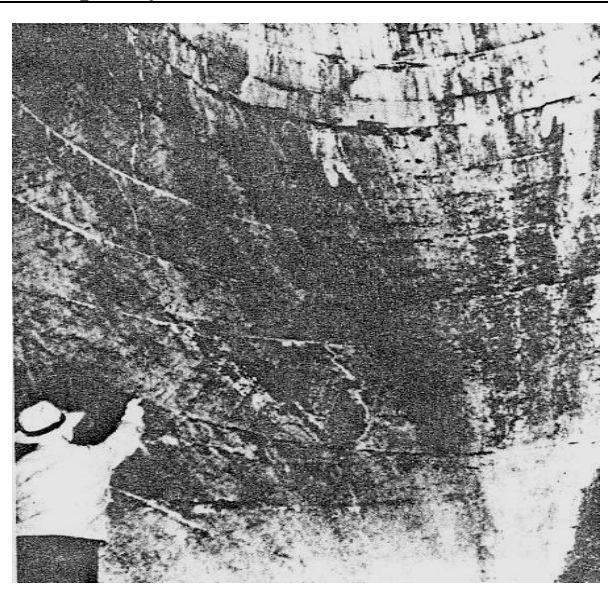

Gibson hydroelectric complex in the USA

Fig. 5. The surface of the coupled bends with traces of concrete cavitation erosion 
When water moves on a concave surface, centrifugal hydrodynamic pressure forces counteracting the cavitation develop. However, due to the significant roughness of section joints, centers of cavitation corrosion of concrete still appeared.

\section{Results and Discussion}

All these disadvantages of hydraulic calculations and shaft spillway design can be eliminated by replacing the circular cylindrical cross-section of the inner surface of the shaft for a polygonal cross-section [13,14, 15, and 16]. Outlets of shaft spillways are designed for a free flow mode of operation with the recommended cross-section with flat side walls and a bottom [17]. For the seamless joints of the drainage surface components and the surfaces of the outlet, the number of sides of the cross-section of the shaft drainage surface should be divisible by four. In the case of such arrangement of the shaft drainage surface, the cross-section of the coupled bend should have a rectangle shape. Opposite pairs of drainage surface sectors arranged orthogonally to each other should be made in the form of a curved trapezoid. In this case, two mutually parallel sectors of the shaft drainage surface will mate with the side walls of the mating joint, the bend from the upstream side will be coupled with its bottom surface, and the bend from the downstream side will form a contracted outlet cross-section of the shaft at the inlet to the coupled bend. Such arrangement of the coupled bend and the outlet conduit forms free water flow throughout the entire operational range of the shat spillway.

The quadruple condition for the number of sides of the cross-sectional polygon of the inner surface of the shaft leads to the following row of polygons: 4, 8 and 12 sides.

Figure 6 shows the plans of the shaft of polygonal cross-sections: tetragonal 6-a, octagonal 6-b and dodecagonal 6-c.

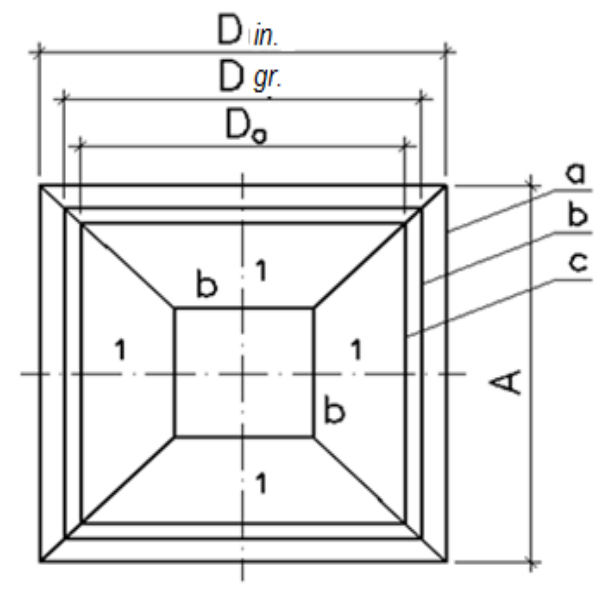

a)

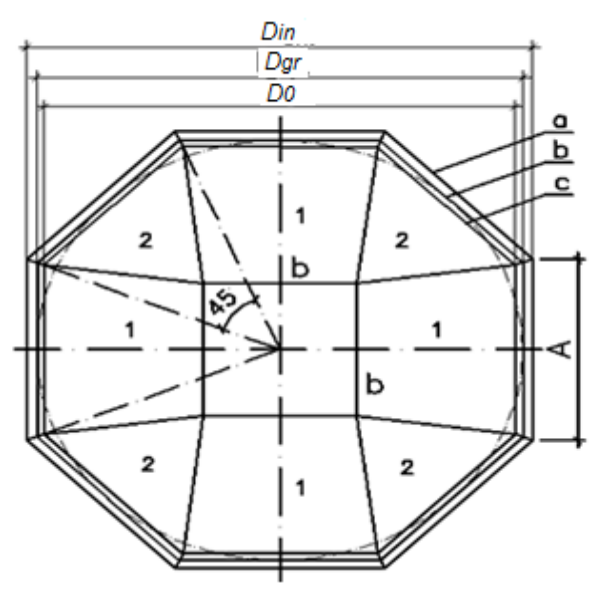

b) 1-trapezoid faces; 2-triangular faces 


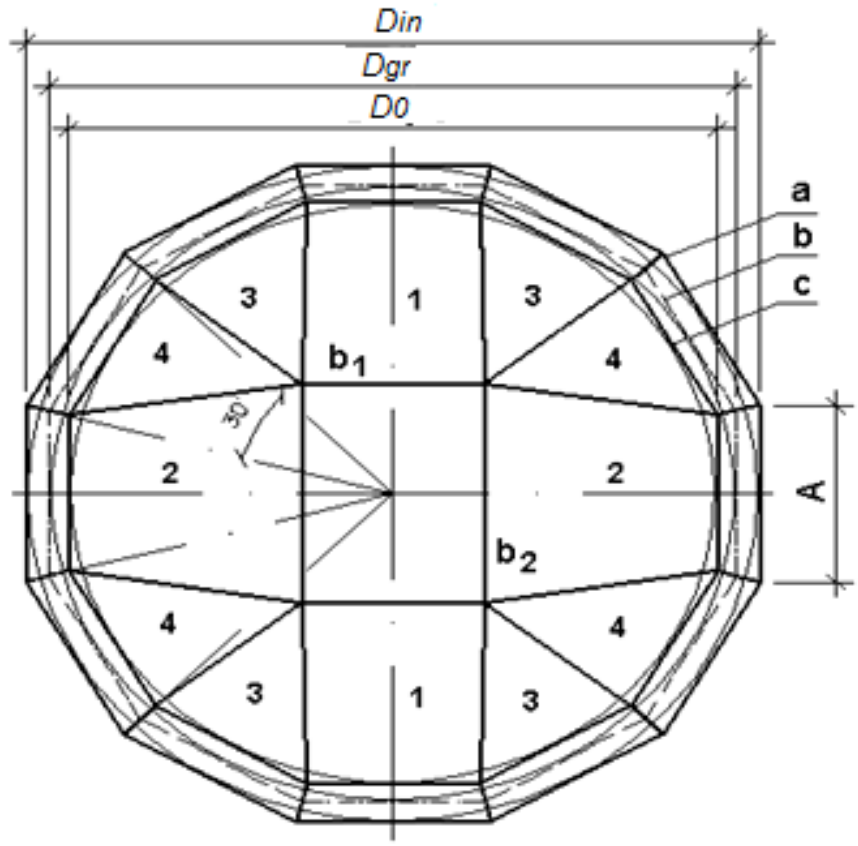

c)

Fig. 6. The shaft plan with a polygonal cross-section: the plans of the shaft of polygonal crosssections: a) - with tetragonal receiving hopper; b) - with octagonal receiving hopper; c) - with dodecagonal receiving hopper; 1,2 - trapezoid faces; 3,4 - triangle faces.

The letters in Figure 6 designate the following elements: $-A$ is the length of the outer rib of the spillway plane; - $D_{i n}$ ia the diameter of the incircle of the outer border of the hopper; $D_{g r}$ ia the diameter of the incircle of the hopper crest; - $D_{o}$ ia the diameter of the incircle of the conjugation line of the hopper crest and the spillway shaft face; - $b$ ia the side of the square outlet section of the shaft; $-b_{1}$ and $b_{2}$ are sides of the rectangular outlet section of the shaft.

Figure 6 shows that according to the project conditions, the trapezoidal sections are directly coupled to each other in the case of a tetragonal cross-section. In the case of an octagonal cross-section, the trapezoidal sections are coupled to each other through triangular sectors. And in the case of a dodecagonal cross-section, the trapezoidal sections are coupled to each other through two triangular sectors.

A dodecagonal spillway shaft was designed for the Jedra hydroelectric complex in Algeria, and its operation was studied on a hydraulic model of 1:60 scale. According to the project data, the water supply $\mathrm{p}=0.01 \%$, the calculated transformed discharge $\mathrm{Q}_{\mathrm{p}=0,01 \%}=740$ $\mathrm{m}^{3} / \mathrm{s}$ should flow with a head $\mathrm{H}=3.28 \mathrm{~m}$ at a discharge coefficient $\mathrm{m}=0,44$ through the head outlined by Wagner coordinates. For modelling studies, they chose a dodecagonal crosssection of the shaft with side $\mathrm{b}=6.0 \mathrm{~m}$ and with a round-cylindrical head and an elliptical drainage surface. According to the research data, the maximum discharge coefficient was $\mathrm{m}=0,517$, which made it possible to reduce the maximum discharge to $\mathrm{Q}_{\mathrm{p}=0.01 \%}=636 \mathrm{~m}^{3} / \mathrm{s}$ with a head at the crest of receiving hopper $\mathrm{h}=2.55 \mathrm{~m}$, taking into account the flood transformation. 
Figure 7 shows a longitudinal section (a) and a plan (b) of the shaft of the spillway of the Jedra hydroelectric complex, and Figure 8 shows a model of dodecagonal water receiving hopper.
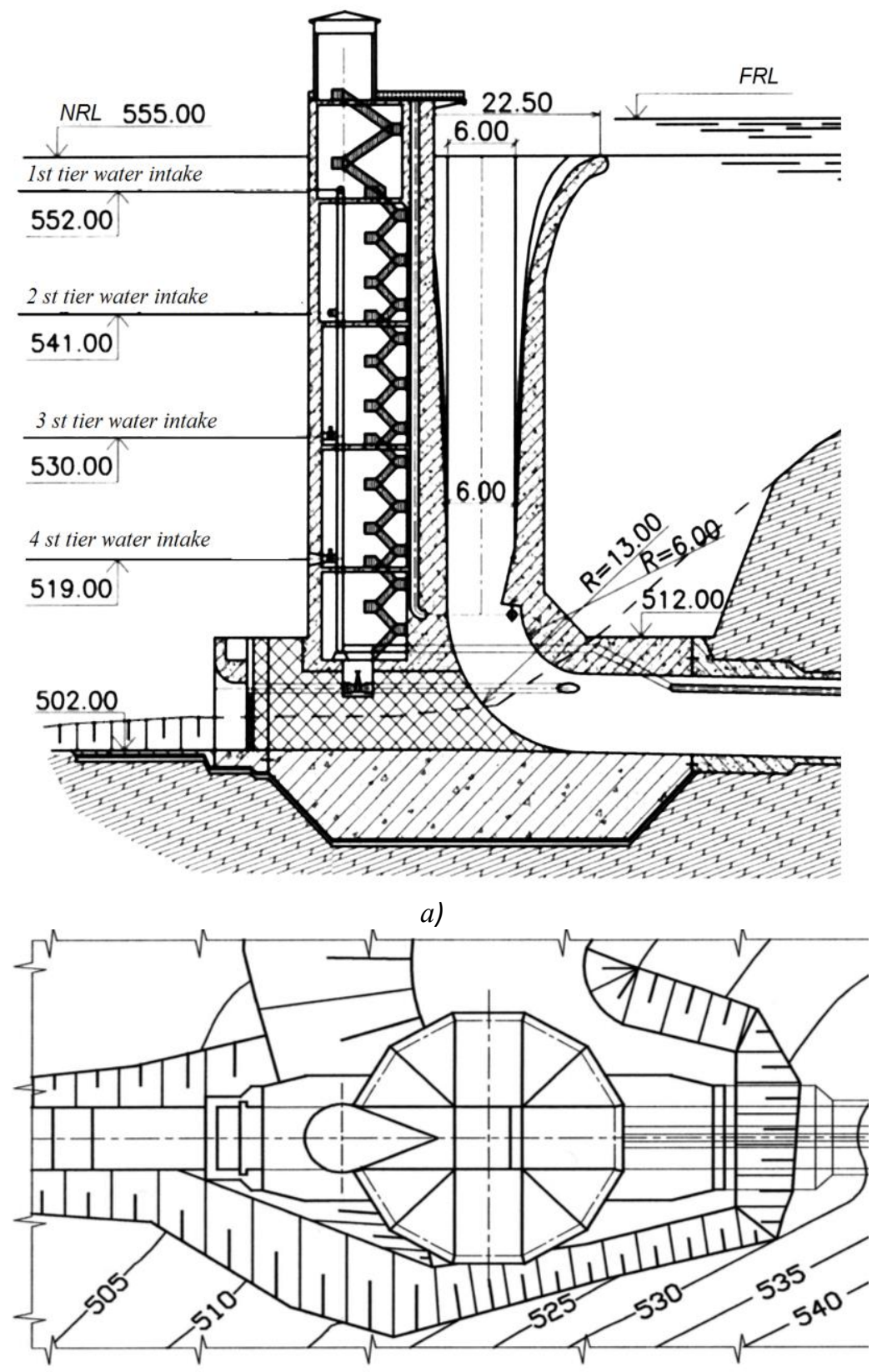

b)

Fig. 7. Shaft spillway of the Jedra hydroelectric complex a is longitudinal section of the spillway shaft; $b$ is shaft spillway plan 


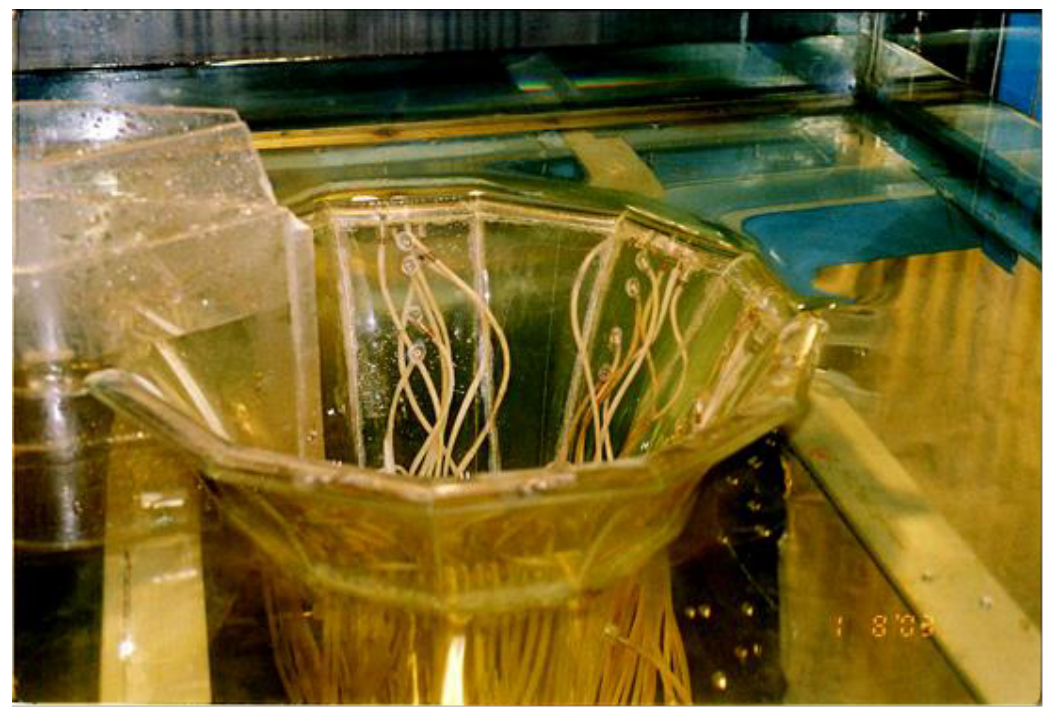

Fig. 8. Dodecagonal water receiving hopper of the model of the shaft spillway of the Jedra hydroelectric complex

Figure 8 shows the flow on the entire drainage surface of the receiving hopper is so still that its presence can be determined only by the distortion of the model's supporting elements on the steep bends of the free surface.

Figure 9 shows the receiving hopper of the shaft spillway at the Monticello hydroelectric complex when operating with a low head.

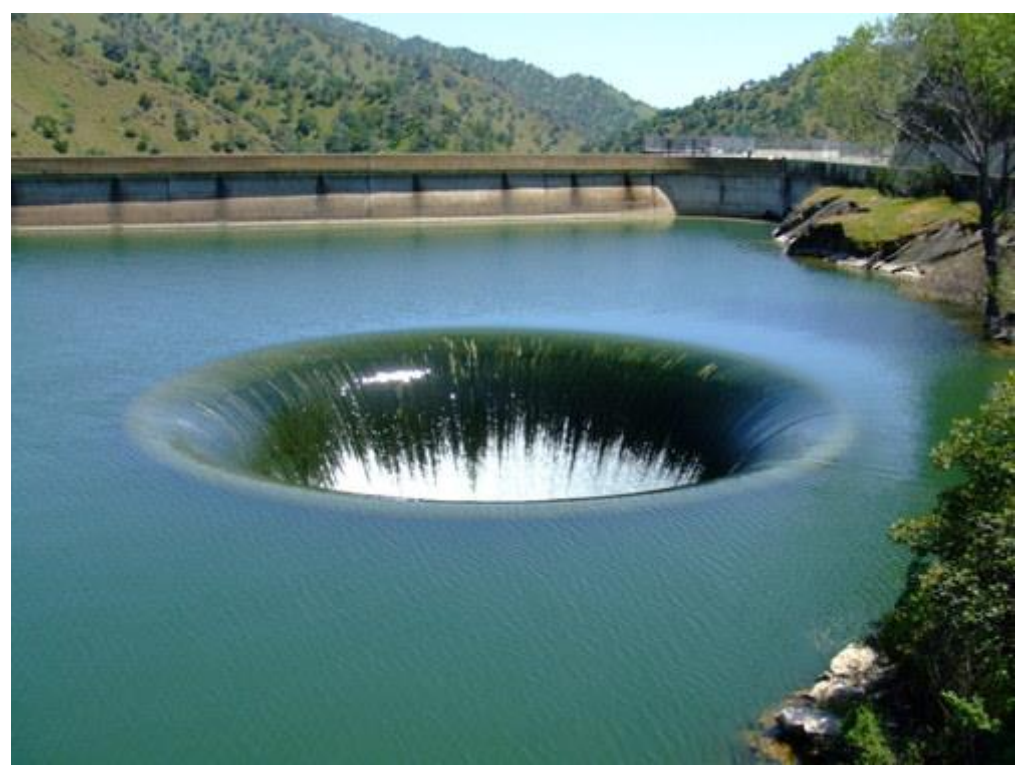

Fig. 9. A receiving hopper of the shaft spillway at the Monticello hydroelectric complex when operating with a low head

The picture shows that the flow is separated and air penetrates into the under-jet space at the joint of the first and second sections of the drainage surface of the hopper (see Figure 
4). The design head on the crest of the receiving hopper of this shaft spillway is $n=4.6 \mathrm{~m}$. Obviously, with the increase in the head and the thickness of the jet, the air will no longer get under the jet, and deep vacuum areas will form in the centers of its separation.

Four shaft spillways with an octagonal cross-section and two shaft spillways with tetragonal cross-sections of the shaft were designed for the Syrian Arab Republic.

Figure 10 shows a longitudinal section of the shaft and the plan of the shaft spillway at the Daifa hydroelectric complex, designed for discharge $\mathrm{Q}=366.7 \mathrm{~m}^{3} / \mathrm{s}$ with head $\mathrm{H}=2.59 \mathrm{~m}$ through octagonal receiving hopper with a side $b=5.40 \mathrm{~m}$.

Figure 11 shows a longitudinal section of the shaft and the plan of the shaft spillway at the Shakra hydroelectric complex, designed for discharge $Q=79.8 \mathrm{~m}^{3} / \mathrm{s}$ with head $\mathrm{H}=1.39 \mathrm{~m}$ through octagonal receiving hopper with side $b=3.0 \mathrm{~m}$.

Figure 12 shows a longitudinal section of the shaft and the plan of the shaft spillway at the Kshatriya hydroelectric complex, designed for discharge $Q=106.7 \mathrm{~m}^{3} / \mathrm{s}$ with head $\mathrm{H}=1,29 \mathrm{~m}$ through octagonal receiving hopper with a side $\mathrm{b}=3.94 \mathrm{~m}$.

Figure 13 shows a longitudinal section of the shaft and the plan of the shaft spillway at Kadmus hydroelectric complex, designed for discharge $\mathrm{Q}=46.3 \mathrm{~m}^{3} / \mathrm{s}$ with head $\mathrm{H}=1.14 \mathrm{~m}$ through octagonal receiving hopper with a side $b=2.50 \mathrm{~m}$.

Figure 14 shows a longitudinal section of the shaft and the plan of the shaft spillway at Beitl el Hajj hydroelectric complex, designed for discharge $Q=126.6 \mathrm{~m}^{3} / \mathrm{s}$ with head $\mathrm{h}=1.59$ $\mathrm{m}$ through tetragonal receiving hopper with a side $\mathrm{b}=8.66 \mathrm{~m}$.

Figure 15 shows a longitudinal section of the shaft and the plan of the shaft spillway at the Karm Mgazel hydroelectric complex, designed for discharge $Q=64.6 \mathrm{~m}^{3} / \mathrm{s}$ with head $\mathrm{H}=1.12 \mathrm{~m}$ through tetragonal receiving hopper with a side $\mathrm{b}=7.70 \mathrm{~m}$.
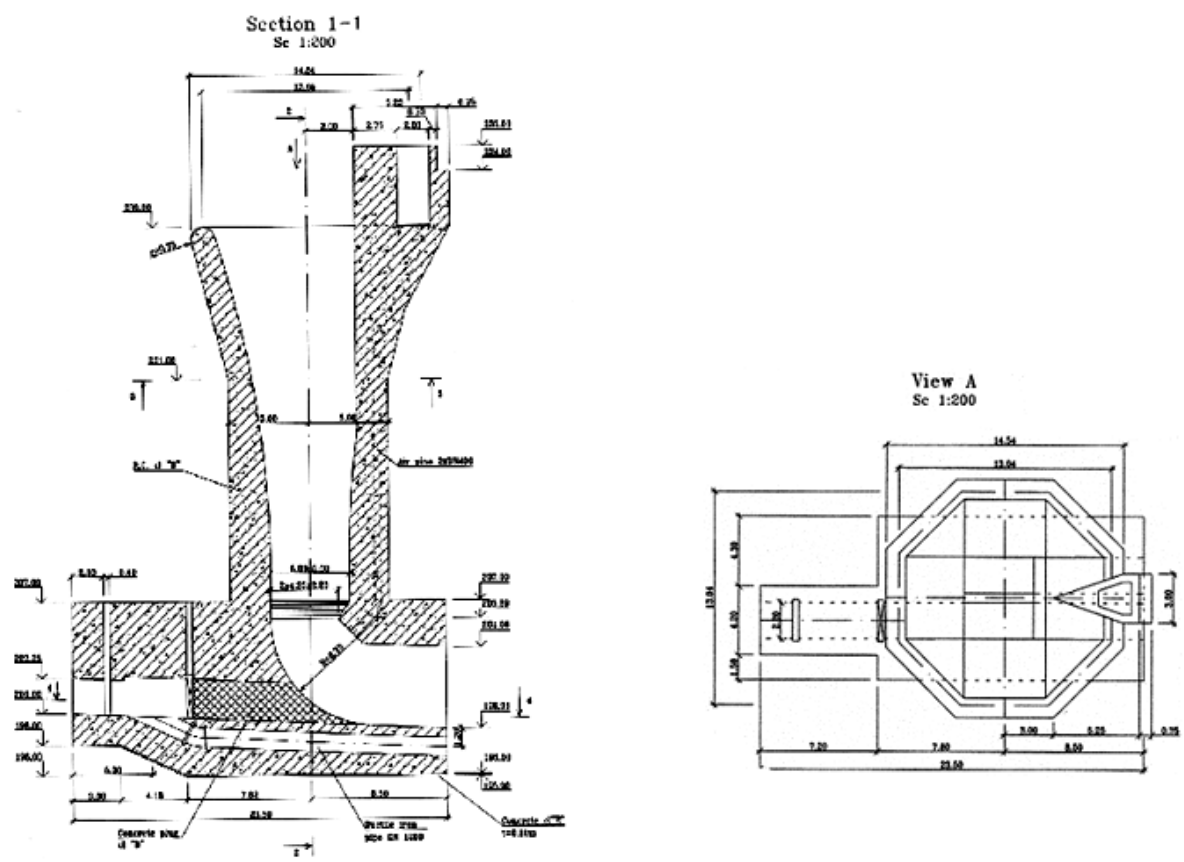

Fig. 10. Longitudinal section of the shaft and the plan of the shaft spillway at the Daifa hydroelectric complex 

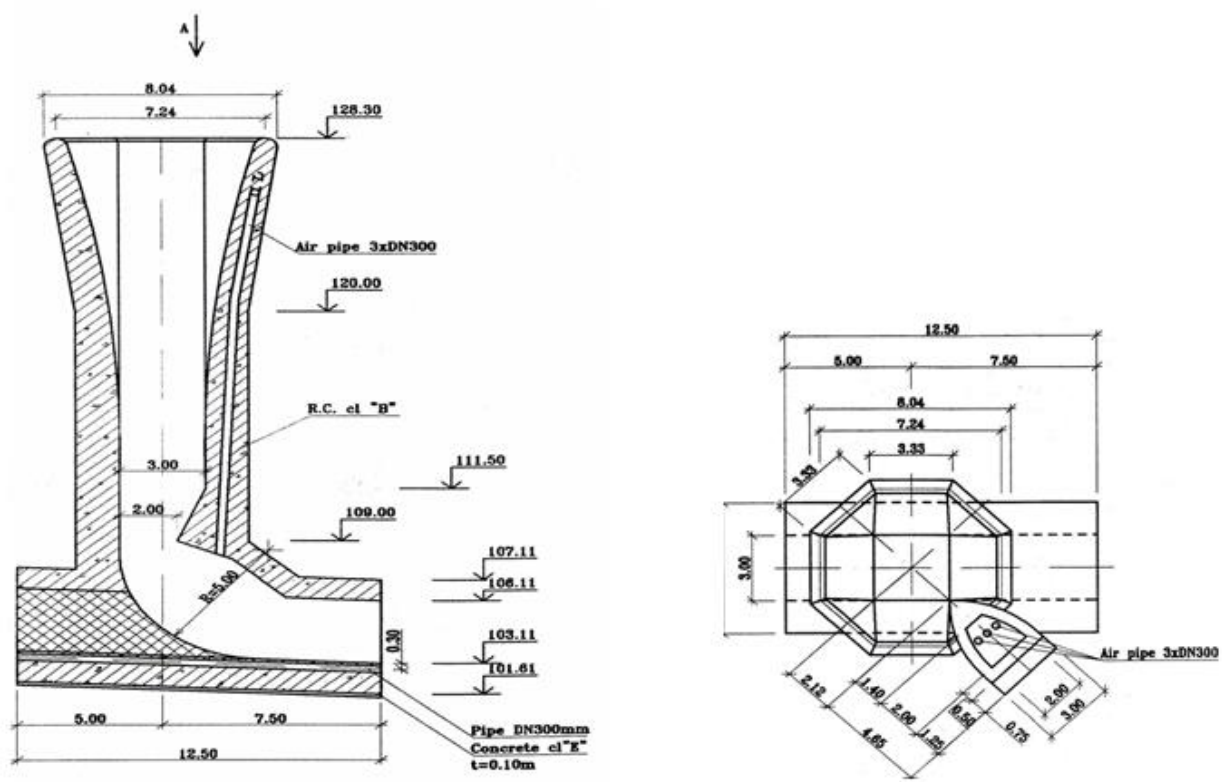

Fig. 11. Longitudinal section of the shaft and the plan of the shaft spillway at the Shakra hydroelectric complex

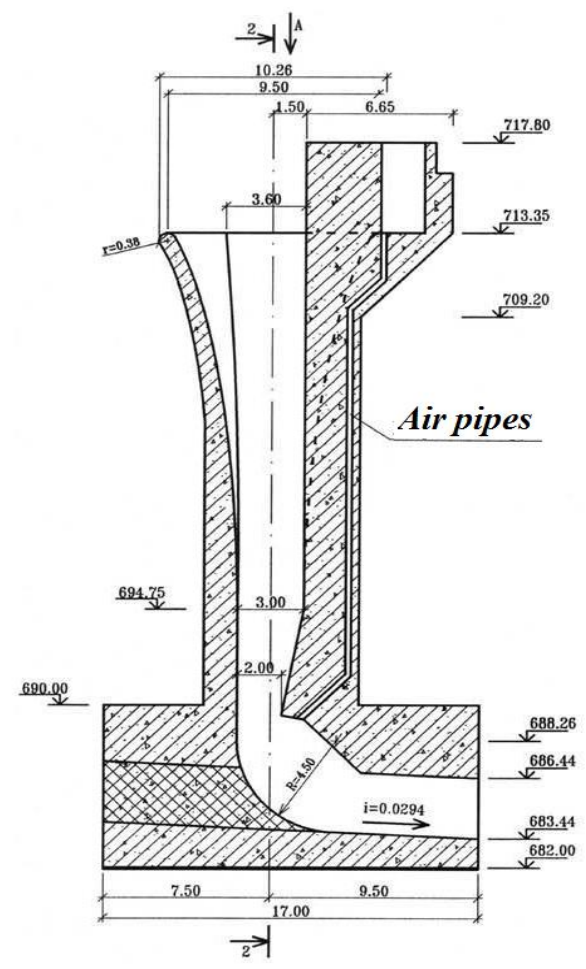

View A

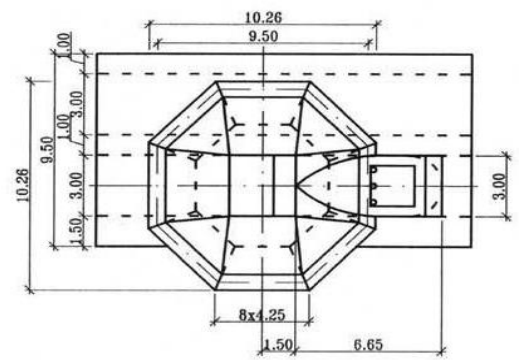

Fig. 12. Longitudinal section of the shaft and the plan of the shaft spillway at the Kshatriya hydroelectric complex 

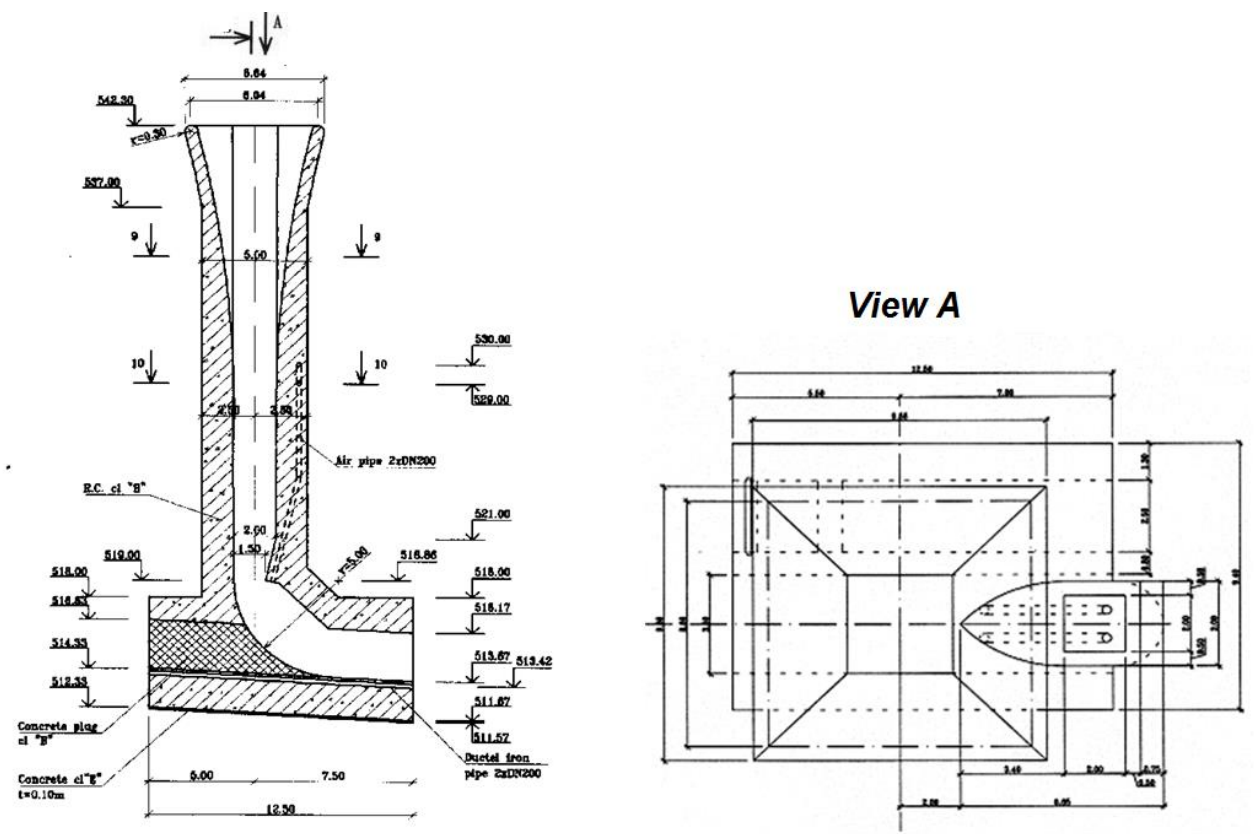

Fig. 13. Longitudinal section of the shaft and the plan of the shaft spillway at the Kadmus hydroelectric complex

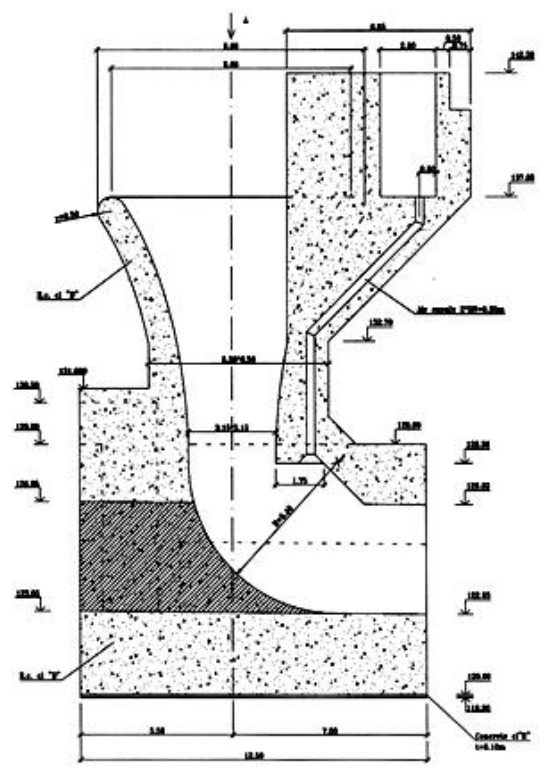

\section{View A}

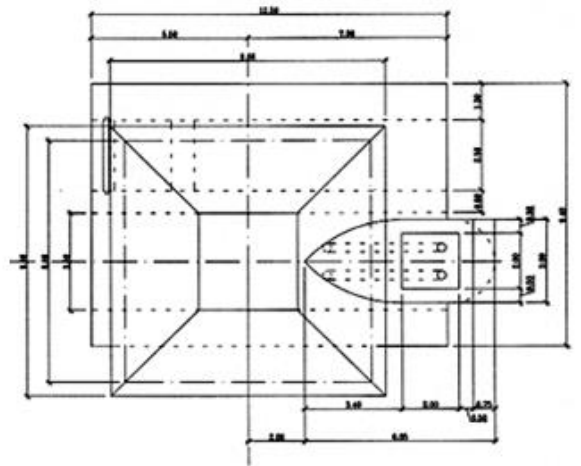

Fig. 14. Longitudinal section of the shaft and the plan of the shaft spillway at the Beitl el Hajj hydroelectric complex 


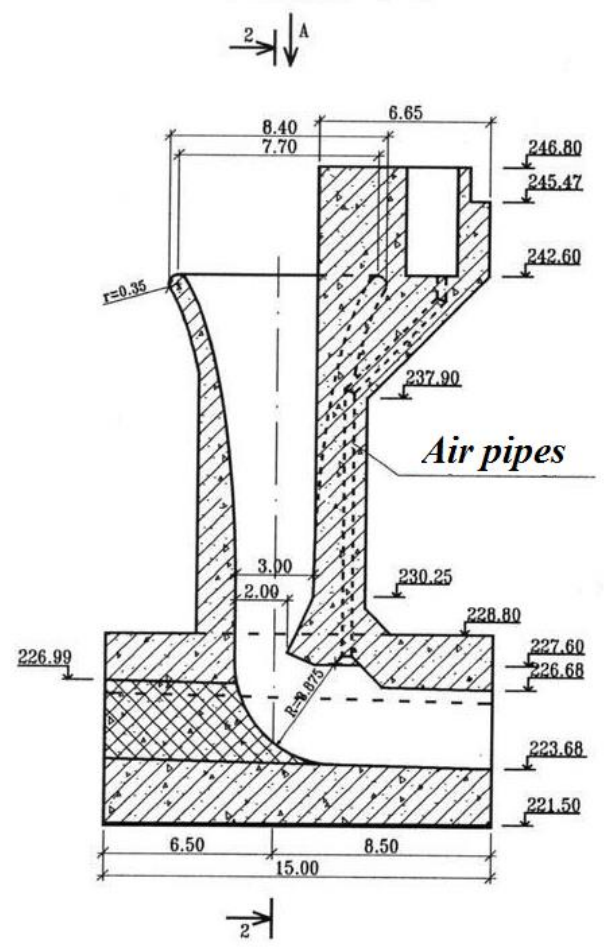

View A

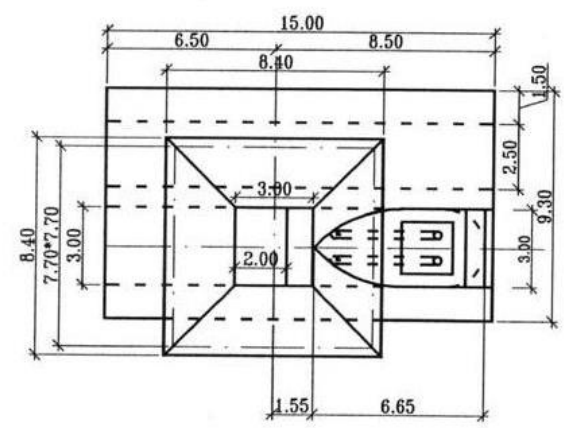

Fig. 15. Longitudinal section of the shaft and the plan of the shaft spillway at the Karm Mgazel hydroelectric complex

\section{Conclusions}

The materials presented prove that shaft spillways with a polygonal cross-section simplify construction technology and build structures with design parameters.

The use of the receiving hopper with a round-cylindrical head allows reducing the required head on the crest of the receiving hopper and reducing the height and cost of the dam.

\section{References}

1. Mois P.P. Shaft spillway, p. 78, Moscow, (1970)

2. Dams for hydroelectric power in Italy. Vol. 5. pp. 147-158, Anigel, (1953)

3. Wagner W.E. Morning - glory shaft spillway: determination of pressure controlled profiles. Proc. ASCE 1954, 80, № 432, (1954)

4. Kiselev P. G. Handbook of hydraulic resistances, p. 312, Moscow, Energiya, (1972)

5. Zuykov A. L., Volgina L.V. Ministerstvovo obrazovaniya i nauki RF, Moskovskiy gosudarstvennyy universitet, p. 424, Moscow, (2014)

6. Novak P., Moffat A.I.B., Nalluri C., Narayanan R. Hydraulic structures, p. 894, London and New York, (2003) 
7. Moys P.P. On the issue of calculating shaft spillways. / Trudy moskovskogo inzhenerno-stroitel'nogo instituta, 24, pp. 81-97, (1959)

8. Moys P.P. Large-scale corrections to the flow coefficient of circular spillway funnels in the plan, Trudy moskovskogo inzhenerno-stroitel'nogo instituta, 46, pp. 118-123, (1964)

9. Rasskazov L.N. Hydraulic structures (river structures). Part 1. Moscow: Publishing house Assotsiatsii stroitel'nykh vuzov, p. 576, (2008)

10. Rasskazov L. N. Hydraulic structures (river structures). Part 1. Moscow: Publishing house Assotsiatsii stroitel'nykh vuzov, p. 584, (2011)

11. E-resource Final dark world. Shaft spillway of Lake Berryessa.

12. Bredley I.N. Morning-Glory shaft spillway: prototype behavior. - Proceedings of the American Society of civil engineers. Discussion Separaten. New York, 80, № 451, (1954)

13. Gur'yev A.P., Afanas'yev A.Y. Shaft spillway, Patent RF, №2250951. Bulletin № 12, 27.04.2004.

14. Gur'yev A.P. Shaft spillway, Patent RF, №2341615. Bulletin №12, 35, 20.12.2007.

15. Gur'yev A.P. Shaft spillway tower-type of polygonal cross-section, Collection of scientific works MSUEE, Moscow, (2004)

16. Gur'yev A.P. Improvement structure of shaft spillway, Izvestiya VNIIG im. B.E. Vedeneeva, Vol. 254.

17. Rozanov N.P. Hydraulic structures, p. 647, Moscow, (1978)

18. Bazarov D., Vatin N., Obidov B., and Vokhidov O. Hydrodynamic effects of the flow on the slab of the stand in the presence of cavitation. IOP Conf. Ser. Mater. Sci. Eng. 1030, 012110 (2021).

19. Bazarov D. and Vokhidov O. Extinguishing Excess Flow Energy in Spillway Structures. In book: Proceedings of EECE 2020, LNCE 150, pp. 535-545, (2021) DOI: 10.1007/978-3-030-72404-7_52

20. Obidov B., Vokhidov O., Tadjieva D., Kurbanova, U., Isakov A. Hydrodynamic effects on the flow elements of the downstream devices in the presence of cavitation. IOP Conf. Ser. Mater. Sci. Eng. 1030, 012114 (2021).

21. Obidov, B., Choriev, R., Vokhidov, O. \& Rajabov, M. Experimental studies of horizontal flow effects in the presence of cavitation on erosion - free dampers. IOP Conf. Ser. Mater. Sci. Eng. 883, 012051 (2020).

22. Obidov, B., Vokhidov, O., Shodiev, B., Ashirov, B. \& Sapaeva, M. Hydrodynamic loads on a water drain with cavitation quenchers. IOP Conf. Ser. Mater. Sci. Eng. 883, 012011 (2020). 